\title{
Serum Concentrations and Hypoglycemic Effect of Gliclazide:Crosspovidone Solid Dispersion on Streptozotocin Induced Diabetic Rats
}

\author{
Authors \\ K. Adibkia ${ }^{1,2}$, H. Babaei ${ }^{1,2}$, S. Asnaashari ${ }^{1}$, S. Andalib ${ }^{1,2}$, A. Khorrami ${ }^{1,2}$, H. Ghavimi ${ }^{1,2}$, V. Jadidinia ${ }^{2,3}$, \\ H. Hajiloo ${ }^{2,3}$, M. Barzegar-jalali ${ }^{1,2}$ \\ Affiliations \\ ${ }^{1}$ Drug Applied Research Center, Tabriz University of Medical Science, Tabriz, Iran \\ ${ }^{2}$ Faculty of Pharmacy, Tabriz University of Medical Science, Tabriz, Iran \\ 3Students' Research Committee, Tabriz University of Medical Science, Tabriz, Iran
}

Key words
gliclazie
solid dispersion
cogrinding
crosspovidone
in vivo
absorption

received $\quad 10.12 .2012$

accepted 16.12.2012

\section{Bibliography}

DOI http://dx.doi.org/

10.1055/s-0032-1333242

Drug Res 2013;

63: 94-97

(c) Georg Thieme Verlag KG

Stuttgart · New York

ISSN 2194-9379

\section{Correspondence \\ M. Barzegar-Jalali}

Department of Pharmaceutics

Faculty of Pharmacy

Tabriz University of Medical

Sciences

Golgasht St.

51664 Tabriz

Iran

Tel.: + 98/411/339 2615

Fax: + 98/411/334 4798

Mahbarja@gmail.com

\section{Abstract}

$\nabla$

Gliclazide is practically insoluble in water and its GI absorption is limited by its dissolution rate. Our previously published works indicated that preparing gliclazide-crosspovidone solid dispersion in the drug/ carrier ratio of 1:1 using cogrinding technique is able to enhance drug dissolution rate. The coground of gliclazide-crosspovidone was administrated to the rats and the hypoglycemic effects of pure drug, a physical mixture and the coground were considered in 3 groups of rats weighing 200-250g $(n=6)$. The rats were made diabetic by single intravenous administration of streptozotocin $(60 \mathrm{mg} / \mathrm{kg})$. Each of the rats received a single dose of gliclazide (equivalent to $40 \mathrm{mg} / \mathrm{kg}$ ) as pure drug, physical mixture and coground in an aqueous suspension. Glucose level was assessed via glucometer after collect-

\section{Introduction}

Gliclazide, (1-(3-azabicyclo (3.3.0) oct-3-yl)-3(p-tolysulfonil) urea, is a second-generation hypoglycemic drug used for the treatment of non-insulin dependent diabetes mellitus, or type II diabetes. Its good general tolerability together with low incidence of hypoglycemia, designate the drug to be suitable for diabetic patients with renal impairment and also for elderly patients taking into consideration that reduced renal function may rise the risk of hypoglycemia following the administration of some sulfonylureas $[1,2]$. So therefore, gliclazide could be a drug of choice in long-term sulfonylurea therapy for the control of type II diabetes. Gliclazide is absorbed slowly from the GI tract and reach the peak serum concentrations within $2-8 \mathrm{~h}$ after oral administration of the drug tablet [3]. Gliclazide belongs to class 2 biopharmaceutical classification system (BCS) and the slow absorption of the ing the blood samples from tail vein. Gliclazide concentration in plasma was assessed applying high pressure liquid chromatography. According to 1-way ANOVA, Student-Newman-Keuls test, the coground revealed enhanced hypoglycemic effects as well as higher serum gliclazide concentration relative to pure drug and its corresponding physical mixture in the all sampling times. The area under serum glucose concentration curve vs. time for the pure gliclazide, physical mixture and coground formulations were $3090.5 \pm 79$, $3018.8 \pm 96$ and $2374.0 \pm 73 \mathrm{mg} . \mathrm{h} / \mathrm{dl}$, respectively. Correspondingly, their area under serum gliclazide concentration curve vs. time were $1171.8 \pm 156.8$, $1379.5 \pm 96.2$ and $4827.7 \pm 637.5 \mu \mathrm{g} . \mathrm{h} / \mathrm{ml}$. It follows that; formulation of gliclazide-crosspovidone coground is able to improve oral absorption of the drug.

drug is in consequence of its poor dissolution from the formulation $[4,5]$. Several methods are used to enhance the dissolution rate of poorly water-soluble drugs. These methods include particle size reduction [6]; solubilization in surfactant systems [7,8]; formation of water soluble complexes [9]; drug derivatization such as strong electrolyte salt forms that commonly have a higher dissolution rate [9]; formulation of liquisolid [10-12], decreasing crystallinity of the drug substance via formation of solid solutions [13], and solid dispersion formulations [14-16]. Solid dispersions as a most popular, simple and less expensive technique $[9,17,18]$, improve drug aqueous solubility/ dissolution rate through decrease of the drug particle size, partial transformation of the crystalline drug to the amorphous state, formation of solid solutions, formation of water soluble complexes, reduction of aggregation and agglomeration, improved wetting of the drug and solubilization of the drug 
by the carrier at the diffusion layer [19-23]. Cogrinding can be applied to improve the dissolution rate of the poorly water-soluble drugs [9,24-28]. This method is ecologically suitable method as unlike other techniques of solid dispersion preparation it does not necessitate toxic solvents and complex equipment [9]. Our recently published works evidenced that cogrinding of gliclazide with crosspovidone in the drug to carrier ratio of 1:1 could efficiently improve the dissolution rate of the drug [9]. In the current study, solid dispersion of gliclazide with crosspovidone was prepared by cogrinding technique in the drug to carrier ratio of $1: 1$. Then, the hypoglycemic effects and serum concentrations of pure drug, a physical mixture and the corresponding solid dispersion were investigated on streptozotocin induced diabetic rats. To the best of our knowledge, hypoglycemic effects and serum concentrations of gliclazide-crosspovidone coground has not been investigated by the other researchers.

\section{Materials and Methods}

$\nabla$

\section{Materials}

Gliclazide (Labching, Italy) and Glyburide (Chinoin Pharma, Hungaria) were provided by Abidi Co. (Tehran, Iran). Streptozotocin (Sigma, Germany), crosspovidone (BASF, Germany), Glucose assay kit (Arkray, Japan) were used. All other chemicals used were of analytical grade.

\section{Preparation of coground formulation and physical mixture}

Unground gliclazide powder ( $5 \mathrm{~g}$ ) and crosspovidone $(5 \mathrm{~g}$ ) were mixed and charged into the chamber of the vibration ball mill (Fritsch, Germany) with the drug-carrier ratios of $1: 1$. About half of the volume of the ball mill chamber was filled by 55 steel balls with various diameters varying $8-20 \mathrm{~mm}$ as well as the powder mixture. The powder mixture was subsequently ground at 360 rotations per minute for $3 \mathrm{~h}$. The samples were collected, labeled and stored in a glass vial before use. The physical mixtures of drug: carrier with the ratio of $1: 1$ was prepared by simply blending the drug and carrier powder [9].

\section{Streptozotocin-induced diabetes model}

Diabetes was induced in the adult male rats weighing 200-250 g by intraperitoneal injection of STZ ( $60 \mathrm{mg} / \mathrm{kg}$ ) dissolved in $0.5 \mathrm{ml}$ citrate buffer $(0.1 \mathrm{M}, \mathrm{pH}=4.6)$. The permission for animal studies was obtained from the ethics committee of Tabriz University of Medical Sciences. All animal experiments were also carried out in compliance with the "Guide for the Care and Use of Laboratory animals" of Tabriz University of Medical Sciences. Fasting blood glucose levels were measured $48 \mathrm{~h}$ after STZ injection and rats with blood glucose levels over $200 \mathrm{mg} / \mathrm{dl}$ were classified as diabetic.

\section{Serum glucose concentration}

The diabetic rats were randomly divided into 3 groups (6 rats/ group). Each of the rats received a single dose of gliclazide (equivalent to $40 \mathrm{mg} / \mathrm{kg}$ ) as pure drug (group A), physical mixture of drug (group B) and solid dispersion (group C) in an aqueous suspension. The suspensions were prepared by dispersing the pure drug powder or its solid dispersion and physical mixture in $10 \mathrm{ml}$ distilled water and administered in the esophagus with a syringe equipped with a number 12 catheter. The animals were fasted $12 \mathrm{~h}$ before the experiment, with free access to water. Blood samples were collected predose $(0 \mathrm{~h})$ and 1, 3, 6 and $8 \mathrm{~h}$ post dose from tail vein. Considering that, in the ascending part of the drug serum concentration curve, the absorption rate is dominant compared to elimination rate and the dissolution rate is the major factor affecting the serum concentrations, attempts were not made to collect the blood samples beyond $8 \mathrm{~h}$. Glucometer (Arkray, Japan) was used to analysis of serum glucose concentration from the collected blood samples. In order to analysis of drug serum concentration, the blood samples centrifuged at $3500 \mathrm{rpm}$ for $15 \mathrm{~min}$, and the serums were collected and kept at $-20^{\circ} \mathrm{C}$.

\section{Gliclazide serum concentration}

Gliclazide concentration in plasma was measured by an established HPLC method $[29,30]$ with slight modification. Briefly, $10 \mu \mathrm{L}$ of glyburide $(1 \mathrm{mg} / \mathrm{mL})$ as an internal standard was added to $100 \mu \mathrm{L}$ of plasma sample and vortex-mixed for $10 \mathrm{~s}$. After that, $200 \mu \mathrm{L}$ of acetonitrile was added to the mixture and was vortexmixed for $10 \mathrm{~s}$ once again and followed by centrifugation at $13000 \mathrm{rpm}$ for $3 \mathrm{~min}$. The dried residue of the acetonitrile extract obtained under vacuum at $40^{\circ} \mathrm{C}$ was redissolved in $100 \mu \mathrm{LH}_{2} \mathrm{PO}_{4}(\mathrm{pH}=4.6)$-acetonitrile $(30: 70 \mathrm{v} / \mathrm{v})$ as a mobile phase, and a $20 \mu \mathrm{L}$ aliquot was injected into the HPLC system. The mobile phase was delivered at the flow rate of $1 \mathrm{ml} / \mathrm{min}$ and separation was achieved on a C18 column $(4.6 \times 250 \mathrm{~mm}, 5 \mu, \mathrm{MZ}$ Analysentechnik GmbH, Mainz, Germany). Gliclazide was detected at $229 \mathrm{~nm}$ wavelength with an ultraviolet detector. Chromatographic data was evaluated applying Data Control program supplied with the HPLC system. A linear calibration plot prepared using peak height of the standard solutions $(0.0125$ $0.1 \mathrm{mg} / \mathrm{ml}$ ) of gliclazide was employed to analyze the concentration of the drug in the serum samples.

\section{Statistical analysis}

1-way ANOVA, Student-Newman-Keuls method was conducted to compare the mean drug serum concentrations at different times for 3 different treatments [31]. Data was represented as mean values \pm SEM (standard error of means). A p-value less than 0.05 was assumed for the statistically significant differences.

\section{Results}

\section{$\nabla$}

\section{Serum glucose concentration}

- Fig. 1 demonstrates the effects of pure gliclazide, physical mixture and coground formulations on serum glucose concentrations at different times. Statistical analysis divulges that the serum glucose concentrations following administration of the coground were significantly lower $(p<0.001)$ than those of pure gliclazide and physical mixture in all the times; however, there was no significant difference ( $p>0.05$ ) between the latter 2 formulations ( $\bullet$ Fig. 1). The area under serum glucose concentration curve vs. time $\left(\mathrm{AUC}_{\mathrm{g} 0}^{8}\right)$ for the pure gliclazide, physical mixture and coground formulations were $3090.5 \pm 79,3018.8 \pm 96$ and $2374.0 \pm 73 \mathrm{mg} . \mathrm{h} / \mathrm{dl}$, respectively. The $\mathrm{AUC}_{\mathrm{g} 0}^{\mathrm{t}}$ value for the coground was significantly $(p<0.001)$ higher than the corresponding values for pure gliclazide and physical mixture; whereas there was no significant difference $(p>0.05)$ between the $\mathrm{AUC}_{\mathrm{g} 0}^{8}$ values of pure gliclazide and physical mixture. 


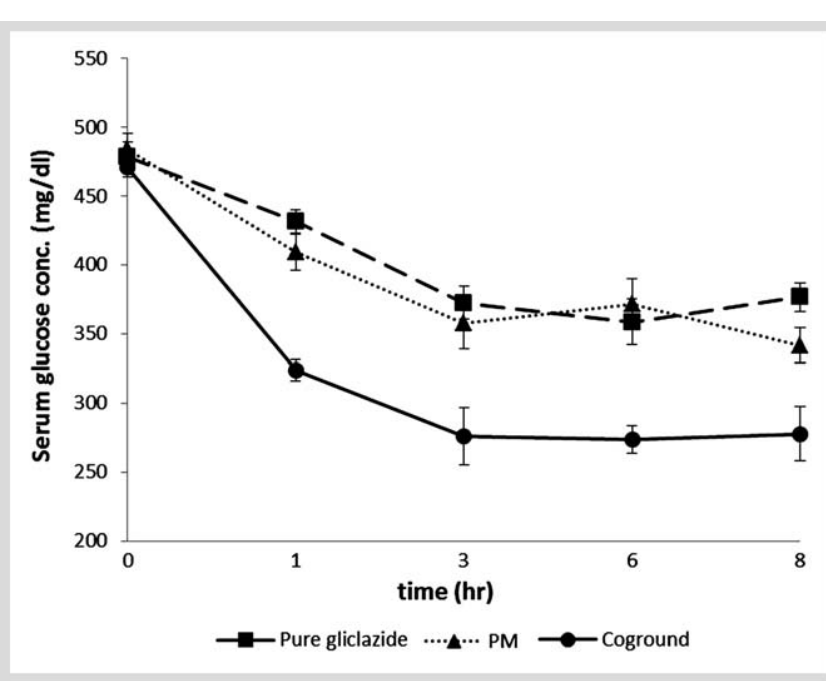

Fig. 1 Mean serum glucose concentration vs. time curve in 6 rats after a single dose of oral administration of pure gliclazide, the physical mixture (PM), and coground. The vertical bars represent the standard error of mean.

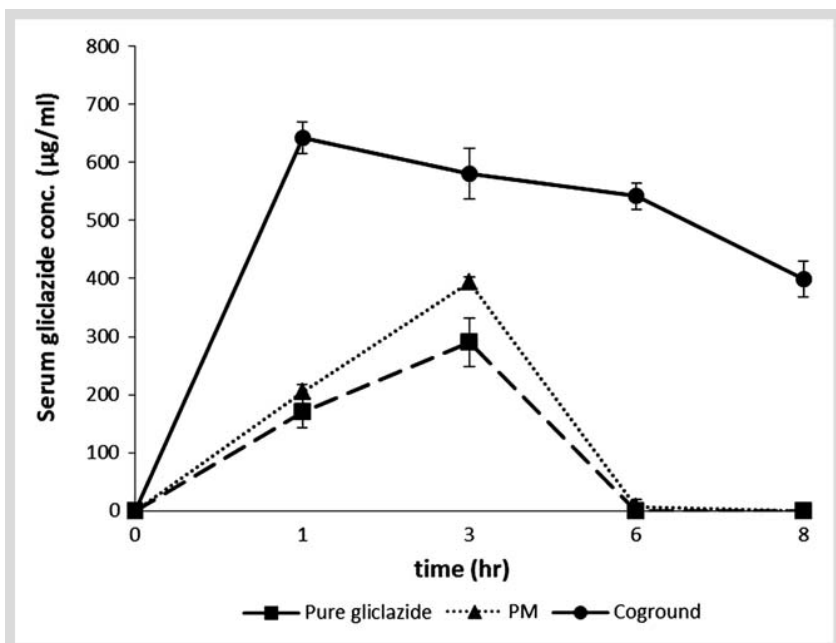

Fig. 2 Mean serum gliclazide concentration vs. time curve in 6 rats after a single dose of oral administration of pure gliclazide, the physical mixture (PM), and coground. The vertical bars represent the standard error of mean.

\section{Gliclazide serum concentration}

Gliclazide serum concentration was measured applying an established HPLC assay with a minor modification $[32,33]$. The retention times for gliclazide and glyburide, used as an internal standard, were 6 and $8 \mathrm{~min}$, respectively. The regression equation for the calibration curve which was obtained by plotting the peak height ratio vs. concentration was as follow:

$y=0.0961 x+0.0042\left(r^{2}=0.9948\right)$

The mean serum concentrations of gliclazide following a single oral dose $(40 \mathrm{mg} / \mathrm{kg})$ of pure gliclazide, physical mixture as well as coground at the different times are shown in 0 Fig. 2 . As in $\odot$ Fig. 2, the serum drug concentrations after administration of the coground were statistically $(\mathrm{p}<0.001)$ higher than those of pure gliclazide, physical mixture in all the sampling times; while there was no statistical difference $(p>0.05)$ between 2 later preparations.
The area under serum gliclazide concentration curve vs. time $\left(\mathrm{AUC}_{\mathrm{SO}}^{8}\right)$ for the pure gliclazide, physical mixture and coground preparations were $1171.8 \pm 156.8, \quad 1379.5 \pm 96.2$ and $4827.7 \pm 637.5 \mu \mathrm{g} . \mathrm{h} / \mathrm{ml}$, respectively. The $\mathrm{AUC}_{\mathrm{S} 0}^{8}$ value for the coground was significantly $(p<0.001)$ higher than those of pure gliclazide and physical mixture; however there was no significant difference $(p>0.05)$ between pure gliclazide and physical mixture.

\section{Discussion \\ $\nabla$}

Our previously published works revealed that the cogrinding method can be employed to enhance the dissolution rate of the poorly water-soluble drug, gliclazide [9]. Our published results pointed out that the coground of gliclazide with crosspovidone in the ratio of $1: 1$ could improve the drug dissolution rate, efficiently [9]. So therefore, in the current study, the mentioned formulation was prepared to investigate the in vivo oral absorption of the solid dispersion in the rats. Administration of the coground could reduce serum glucose concentrations significantly more efficient $(p<0.001)$ than pure gliclazide and physical mixture. The difference in serum glucose concentrations could be explained by corresponding difference in the dissolution profiles, explicitly, the higher dissolution rate lead to the lower serum glucose concentration. The higher dissolution rate can be accounted for the higher hypoglycemic effect of the coground formulation as well. The serum drug concentrations next to coground administration were statistically $(\mathrm{p}<0.001)$ higher than the other preparations. The results were in accordance with serum glucose concentration data indicating that oral absorption of gliclazide enhances after its administration as a coground system with crosspovidone which could be due to enhanced dissolution rate of drug in the coground formulation. Similar results have been reported by Asayrie S., et al. for the solid dispersion of gliclazide with PEG 6000 [34]. Although, precise estimate of pharmacokinetic parameters was not possible because of insufficient plasma sampling data, but it is evident in $\odot$ Fig. 2 that the coground of gliclazide with crosspovidone resulted in considerably higher $C_{\max }$ (the peak plasma concentration) as well as lower $\mathrm{T}_{\max }$ (the time required to reach the peak) in comparison with pure drug and physical mixture.

\section{Conclusion \\ $\nabla$}

As indicated by this study, formulation of gliclazide-crosspovidone solid dispersion directing cogrinding method is able to improve oral absorption of the drug. That is, preparation of gliclazide-crosspovidone coground resulted in elevation of drug serum concentration and decrease of serum glucose concentration. The higher dissolution rate of the coground compared to pure gliclazide and its physical mixture with crosspovidone can be accounted for the higher hypoglycemic effect of the coground formulation.

\section{Acknowledgments \\ $\nabla$}

This article was written based on a dataset of a Pharm. D. thesis, registered in Tabriz University of Medical Sciences. The authors thank Drug Applied Research Center of Tabriz University of Medical Sciences, Tabriz, Iran for financial support of the project. 


\section{Conflict of Interest}

The authors report no conflicts of interest.

\section{References}

1 Palmer KJ, Brogden RN. Gliclazide. An update of its pharmacological properties and therapeutic efficacy in non-insulin-dependent diabetes mellitus. Drugs 1993; 46: 92-125

2 Harrower $A D$. Comparison of efficacy, secondary failure rate, and complications of sulfonylureas. J Diabetes Complications 1994; 8: 201-203

3 Campbell DB, Lavielle R, Nathan C. The mode of action and clinical pharmacology of gliclazide: a review. Diabetes Res Clin Pract 1991; 14: (Suppl 2): S21-S36

4 Delrat $P$, Paraire $M$, Jochemsen R. Complete bioavailability and lack of food-effect on pharmacokinetics of gliclazide $30 \mathrm{mg}$ modified release in healthy volunteers. Biopharm Drug Dispos 2002; 23: 151-157

5 Asyarie $S$, Rachmawati $H$. In vivo and in vitro evaluation of a solid dispersion system of gliclazide:PEG 6000. PDA J Pharm Sci Technol 2007; 61: 400-410

6 Kubo H, Osawa T, Takashima $\mathrm{K}$ et al. Enhancement of oral bioavailability and pharmacological effect of 1-(3,4-dimethoxyphenyl)-2,3bis(methoxycarbonyl)-4-hydroxy-6,7,8-trimethoxynaphthalene (TA-7552), a new hypocholesterolemic agent, by micronization in coground mixture with D-mannitol. Biol Pharm Bull 1996; 19: 741-747

7 Martis L, Hall NA, Thakkar AL. Micelle formation and testosterone solubilization by sodium glycocholate. J Pharm Sci 1972; 61: 1757-1761

8 Rees JA, Collett JH. The dissolution of salicylic acid in micellar solutions of polysorbate 20. J Pharm Pharmacol 1974; 26: 956-960

9 Barzegar-Jalali $M$, Valizadeh H, Siahi Shadbad MR et al. Cogrinding as an approach to enhance dissolution rate of a poorly water-soluble drug (gliclazide). Powder Technology 2010; 197: 150-158

10 Javadzadeh $Y$, Siahi MR, Asnaashari $S$ et al. An investigation of physicochemical properties of piroxicam liquisolid compacts. Pharm Dev Technol 2007; 12: 337-343

11 Javadzadeh Y, Siahi MR, Asnaashari S et al. Liquisolid technique as a tool for enhancement of poorly water-soluble drugs and evaluation of their physicochemical properties. Acta Pharm 2007; 57: 99-109

12 Spireas $S$, Wang $T$, Grover $R$. Effect of powder substrate on the dissolution properties of methyclothiazide liquisolid compacts. Drug Dev Ind Pharm 1999; 25: 163-168

13 Kapsi SG, Ayres JW. Processing factors in development of solid solution formulation of itraconazole for enhancement of drug dissolution and bioavailability. Int J Pharm 2001; 229: 193-203

14 Barzegar-Jalali $M$, Nayebi AM, Valizadeh $H$ et al. Evaluation of in vitroin vivo correlation and anticonvulsive effect of carbamazepine after cogrinding with microcrystalline cellulose. J Pharm Pharm Sci 2006; 9: $307-316$

15 Mohammadi G, Barzegar-Jalali M, Valizadeh $H$ et al. Reciprocal powered time model for release kinetic analysis of ibuprofen solid dispersions in oleaster powder, microcrystalline cellulose and crospovidone. J Pharm Pharm Sci 2010; 13: 152-161

16 Valizadeh H, Zakeri-Milani P, Barzegar-Jalali $M$ et al. Preparation and characterization of solid dispersions of piroxicam with hydrophilic carriers. Drug Dev Ind Pharm 2007; 33: 45-56
17 Kapsi SG, Ayres JW. Processing factors in development of solid solution formulation of itraconazole for enhancement of drug dissolution and bioavailability. Int J Pharm 2001; 229: 193-203

18 Craig $D Q$. The mechanisms of drug release from solid dispersions in water-soluble polymers. Int J Pharm 2002; 231: 131-144

19 Biswal S, Sahoo J, Murthy PN et al. Enhancement of dissolution rate of gliclazide using solid dispersions with polyethylene glycol 6000 . AAPS PharmSciTech 2008; 9: 563-570

20 Craig $D Q$. The mechanisms of drug release from solid dispersions in water-soluble polymers. Int J Pharm 2002; 231: 131-144

21 Ohara T, Kitamura S, Kitagawa $T$ et al. Dissolution mechanism of poorly water-soluble drug from extended release solid dispersion system with ethylcellulose and hydroxypropylmethylcellulose. Int J Pharm 2005; 302: 95-102

22 Ruan $L P, Y u B Y, F u$ GM et al. Improving the solubility of ampelopsin by solid dispersions and inclusion complexes. J Pharm Biomed Anal 2005; 38: 457-464

23 Verheyen S, Blaton N, Kinget $R$ et al. Mechanism of increased dissolution of diazepam and temazepam from polyethylene glycol 6000 solid dispersions. Int J Pharm 2002; 249: 45-58

24 Barzegar-Jalali M, Nayebi AM, Valizadeh $H$ et al. Evaluation of in vitroin vivo correlation and anticonvulsive effect of carbamazepine after cogrinding with microcrystalline cellulose. J Pharm Pharm Sci 2006; 9: 307-316

25 Vogt $M$, Vertzoni $M$, Kunath $K$ et al. Cogrinding enhances the oral bioavailability of EMD 57033, a poorly water soluble drug, in dogs. Eur J Pharm Biopharm 2008; 68: 338-345

26 Vogt M, Kunath K, Dressman JB. Dissolution enhancement of fenofibrate by micronization, cogrinding and spray-drying: comparison with commercial preparations. Eur J Pharm Biopharm 2008; 68: 283-288

27 Vogt M, Kunath K, Dressman JB. Dissolution improvement of four poorly water soluble drugs by cogrinding with commonly used excipients. Eur J Pharm Biopharm 2008; 68: 330-337

28 Wongmekiat A, Tozuka Y, Oguchi T et al. Formation of fine drug particles by cogrinding with cyclodextrins. I. The use of beta-cyclodextrin anhydrate and hydrate. Pharm Res 2002; 19: 1867-1872

29 Asyarie $S$, Rachmawati $H$. In vivo and in vitro evaluation of a solid dispersion system of gliclazide:PEG 6000. PDA J Pharm Sci Technol 2007; 61: 400-410

30 Park JY, Kim KA, Kim SL et al. Quantification of gliclazide by semimicro high-performance liquid chromatography: application to a bioequivalence study of two formulations in healthy subjects. J Pharm Biomed Anal 2004; 35: 943-949

31 Armitage P. Statistical methods in medical research. London: Blackwell Scientific Publications, 1997

32 Asyarie S, Rachmawati $H$. In vivo and in vitro evaluation of a solid dispersion system of gliclazide:PEG 6000. PDA J Pharm Sci Technol 2007; 61: 400-410

33 Park JY, Kim KA, Kim SL et al. Quantification of gliclazide by semimicro high-performance liquid chromatography: application to a bioequivalence study of two formulations in healthy subjects. J Pharm Biomed Anal 2004; 35: 943-949

34 Asyarie $S$, Rachmawati $H$. In vivo and in vitro evaluation of a solid dispersion system of gliclazide:PEG 6000. PDA J Pharm Sci Technol 2007; 61: 400-410 